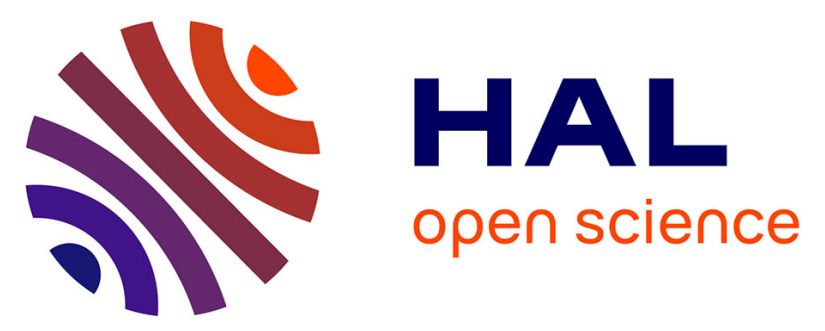

\title{
Integrated broadband dual-polarization Ge-rich SiGe mid-infrared Fourier-transform spectrometer
}

\author{
Qiankun Liu, Joan Manel Ramírez, Vladyslav Vakarin, Xavier Le Roux, \\ Carlos Alonso-Ramos, Enrico Talamas Simola, Jacopo Frigerio, Andrea \\ Ballabio, Enrico Talamas Simola, David Bouville, et al.
}

\section{To cite this version:}

Qiankun Liu, Joan Manel Ramírez, Vladyslav Vakarin, Xavier Le Roux, Carlos Alonso-Ramos, et al.. Integrated broadband dual-polarization Ge-rich SiGe mid-infrared Fourier-transform spectrometer. Optics Letters, 2018, 43 (20), 10.1364/OL.43.005021 . hal-01891844

\section{HAL Id: hal-01891844 https://hal.science/hal-01891844}

Submitted on 10 Oct 2018

HAL is a multi-disciplinary open access archive for the deposit and dissemination of scientific research documents, whether they are published or not. The documents may come from teaching and research institutions in France or abroad, or from public or private research centers.
L'archive ouverte pluridisciplinaire HAL, est destinée au dépôt et à la diffusion de documents scientifiques de niveau recherche, publiés ou non, émanant des établissements d'enseignement et de recherche français ou étrangers, des laboratoires publics ou privés. 


\title{
Integrated broadband dual-polarization Ge-rich SiGe mid-infrared Fourier-Transform spectrometer
}

\author{
Qiankun Liu, ${ }^{1,}{ }^{*}$ Joan Manel Ramirez, ${ }^{1}$ Vladyslav Vakarin, ${ }^{1}$ XaVier Le \\ Roux, ${ }^{1}$ Carlos Alonso-Ramos, ${ }^{1}$ Jacopo Frigerio, ${ }^{2}$ Andrea Ballabio, ${ }^{2}$ \\ Enrico Talamas Simola, ${ }^{2}$ David Bouville, ${ }^{1}$ LaURent Vivien, ${ }^{1}$ GiovanNi \\ ISELLA, ${ }^{2}$ AND DELPHINE MARRIS-MORINI, ${ }^{1}$ \\ ${ }^{1}$ Centre de Nanosciences et de Nanotechnologies (C2N), Université Paris Sud, CNRS, Université Paris Saclay, 91405 Orsay, France \\ ${ }^{2}$ L-NESS, Dipartimento di Fisica, Politecnico di Milano, Polo di Como, Via Anzani 42, 22100 Como, Italy \\ *Corresponding author: qiankun.liu@u-psud.fr
}

Received XX Month XXXX; revised XX Month, XXXX; accepted XX Month XXXX; posted XX Month XXXX (Doc. ID XXXXX); published XX Month XXXX

\begin{abstract}
Miniaturized on-chip spectrometers covering a wide band of the mid-infrared spectrum have an immense potential for multi-target detection in high-impact applications like chemical sensing or environmental monitoring. Specifically, multi-aperture spatial heterodyne Fourier transform spectrometers (SHFTS) provide high throughput and improved tolerances against fabrication errors, compared to conventional counterparts. Still, state-of-the-art implementations have only shown single polarization operation in narrow bandwidths within the near and short infrared. Here, we demonstrate the first dual-polarization ultra wideband SHFTS working beyond $5 \mu \mathrm{m}$ wavelength. We exploit the unique flexibility in material engineering of the graded-index germanium-rich silicon-germanium (Ge-rich SiGe) photonic platform to implement a SHFTS that can be operated in an unprecedented range of $800 \mathrm{~cm}-1$, showing experimental resolution better than $15 \mathrm{~cm}-1$ for both orthogonal polarizations and free-spectral-range of $132 \mathrm{~cm}-1$, in the range between $5 \mu \mathrm{m}$ and $8.5 \mu \mathrm{m}$ wavelength.
\end{abstract}

\section{(C) 2018 Optical Society of America}

http://dx.doi.org/10.1364/OL.99.099999

Molecules can be indubitably identified and quantified through their unique absorption spectra in the mid infrared (MIR) fingerprint region, from 500 to $1500 \mathrm{~cm}^{-1}$. Hence, integrated MIR spectrometers, providing compact sizes, low power consumption and high-performance multi-target detection would have a great potential for a plethora of applications, including medical diagnosis $[1,2]$, astronomy [3], chemical and biological sensing [4,5] or security [6], to name a few. In terms of photonic integration, silicon photonics has shown an excellent potential for developing efficient, compact and cost-effective photonic circuits. Integrated spectroscopic systems have thus been demonstrated based on different approaches such as array waveguide gratings (AWG) [7], echelle gratings [8] or Fourier transform-based spectrometers (FTS) [9-12]. Integrated multi-aperture spatial heterodyne Fourier transform spectrometers (SHFTS) provide high-resolution spectral retrieval, exploiting seamless phase and amplitude correction algorithms to substantially relax fabrication tolerances, compared with conventional counterparts, as typically employed in AWG or echelle gratings [9]. SHFTS rely on an array of Mach-Zehnder interferometers (MZI) with linearly increasing path lengths to implement the spatial heterodyne spectroscopy (SHS), thereby obviating the need for moving parts. In addition, this multi-aperture configuration provides unmatched optical throughput, which is a key aspect for spectroscopic analysis of spatially extended incoherent sources. Up to now, most of the FTS demonstrations use the Silicon-on-Insulator (SOI) platform, which provides a mature technology compatible with near-infrared and short-wave infrared (SWIR) wavelength range. Thus state-of-the-art integrated SHFTS have shown operation mainly at $1.55 \mu \mathrm{m}$ [9-11] and in the SWIR spectral region, below $4 \mu \mathrm{m}$ wavelength [12]. In all cases, the operation is limited to single-polarization because of the polarization dependence of the MZIs, while dual-polarization operation would be highly desirable for applications such as sensing in space satellites or unmanned aerial vehicles. Indeed controlling the polarization of the collected light in such environments is very challenging [13]. In the last years, the development of photonic platforms dedicated to longer MIR wavelengths has witnessed a burst of research activity [14-25]. A wide variety of materials have thus been used to demonstrate photonic integrated circuits operating at wavelengths beyond $4.5 \mu \mathrm{m}$, including III-V semiconductors [15,16], chalcogenides $[17,18]$, suspended silicon approaches [19], Ge-on-Si [20-22] and SiGe alloys [23-25]. Recently, germanium-rich silicon-germanium 
(Ge-rich $\mathrm{SiGe}$ ) has emerged as a promising integrated platform exhibiting a wide transparency range and a strong $3^{\text {rd }}$ order nonlinearity [26,27]. A linearly graded SiGe layer allows a smooth transition between pure silicon and Ge-rich material (see Fig. 1. a) that minimizes the threading dislocation density due to lattice mismatch, while confining the optical mode in the upper part of the waveguide by refractive index gradient. Furthermore, the flexible design of the slope and concentrations of the graded buffer and Gerich layer, respectively, releases new degrees of freedom to shape modal confinement, birefringence and dispersion [28]. These compelling features make the Ge-rich SiGe an excellent technology for next generation spectroscopic systems at long MIR wavelengths. Finally the recent experimental demonstration of broadband MIR interferometers [29] provides a promising departing point to develop new deep MIR spectroscopic systems.
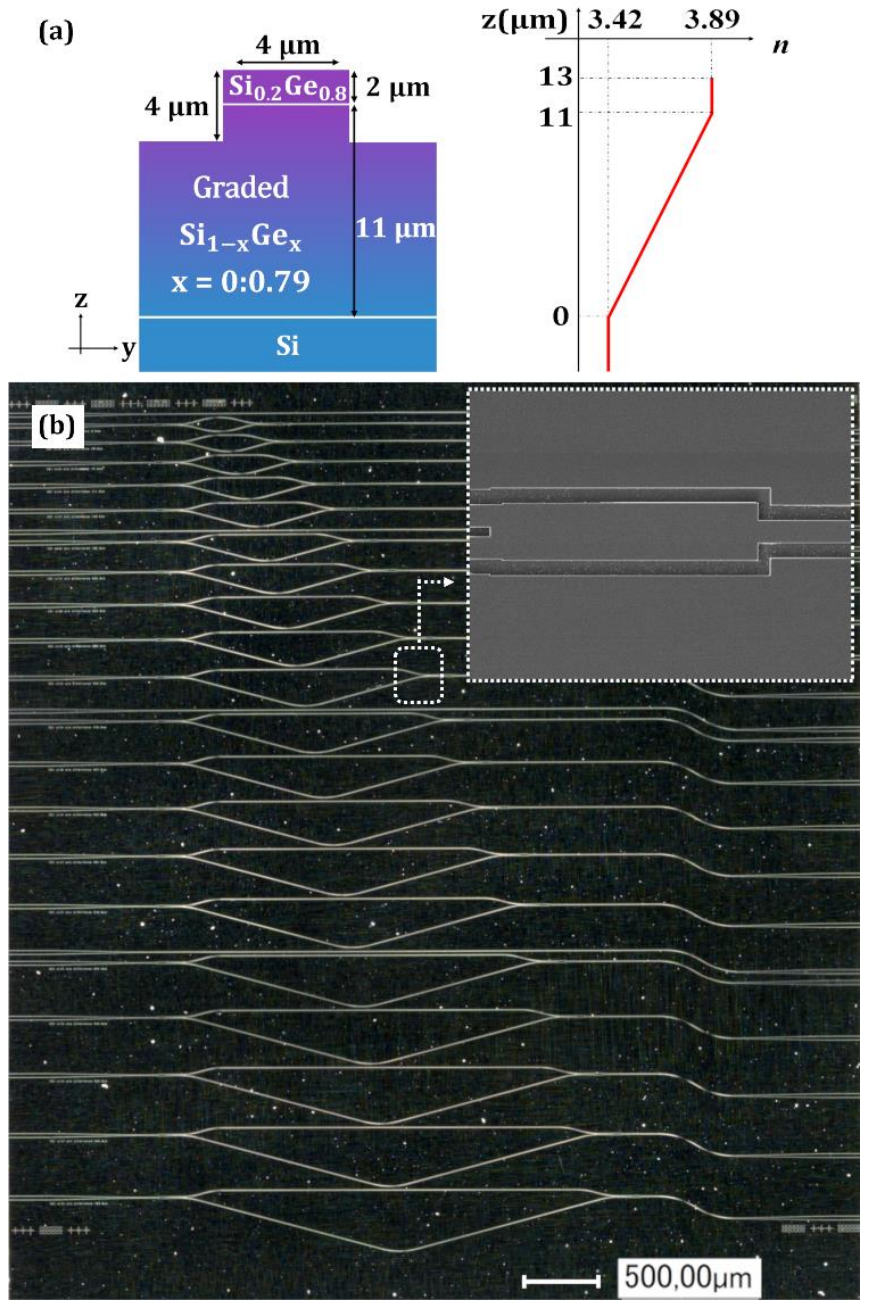

Fig. 1. (a) Schematic view of the waveguide cross-section and its corresponding refractive index at $7.5 \mu \mathrm{m}$ wavelength; (b) Optical microscope image of the MIR Fourier-Transform spectrometer, (inset) SEM image of a multimode interferometer.

In this paper, we experimentally demonstrate an integrated SHFTS implemented in the Ge-rich SiGe technology platform, working in an ultra-wideband range in the MIR, between $5 \mu \mathrm{m}$ (2000 $\left.\mathrm{cm}^{-1}\right)$ and $8.5 \mu \mathrm{m}\left(\sim 1170 \mathrm{~cm}^{-1}\right)$ wavelength, for both transverse electric (TE) and transverse magnetic (TM) polarizations, and with a resolution better than $15 \mathrm{~cm}^{-1}$. The low birefringence and wideband operation is enabled by the gradual index change in the SiGe graded layer, which permits an optimal mode confinement in the considered wavelength range.

The SHFTS is implemented using waveguides based on a $11 \mu \mathrm{m}-$ thick $\mathrm{Si}_{1-\mathrm{x}} \mathrm{Ge}_{\mathrm{x}}$ graded layer with a linearly increasing $\mathrm{Ge}$ concentration $\mathrm{x}$ along the growth direction from 0 (Si) to 0.79 ( $\mathrm{Si}_{0.21} \mathrm{Ge}_{0.79}$ ) followed by a $2 \mu$ m-thick $\mathrm{Si}_{0.2} \mathrm{Ge}_{0.8}$ guiding core layer. Details about device fabrication can be found in [26]. The waveguide facets were defined by mechanical dicing, which provides a reproducible coupling condition with a coupling loss around $4 \mathrm{~dB} /$ facet. Waveguides have an etching depth and width of $4 \mu \mathrm{m}$ (see Fig. 1. a), providing flat propagation loss below $2.5 \mathrm{~dB} / \mathrm{cm}$ from 5 to $8.5 \mu \mathrm{m}$ wavelength for both, TE and TM polarizations [26]. The beam splitters/combiners in the MZIs are implemented by $1 \times 2$ multimode interferometer (MMI), optimized to achieve broadband operation for both TE and TM polarizations in the 5 to $8.5 \mu \mathrm{m}$ wavelength range. The unprecedented ultra-wideband dualpolarization operation of the waveguides and splitters is of fundamental importance to overcome the limitations of conventional SHFTS.

(a)

(b)

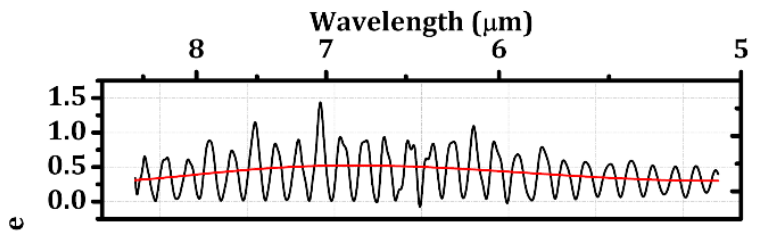

(c)

总 1.0

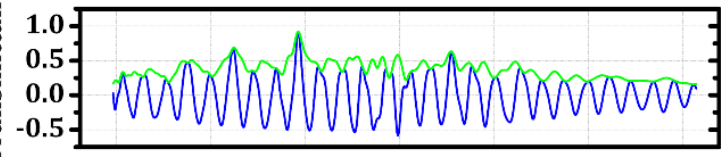

(d)
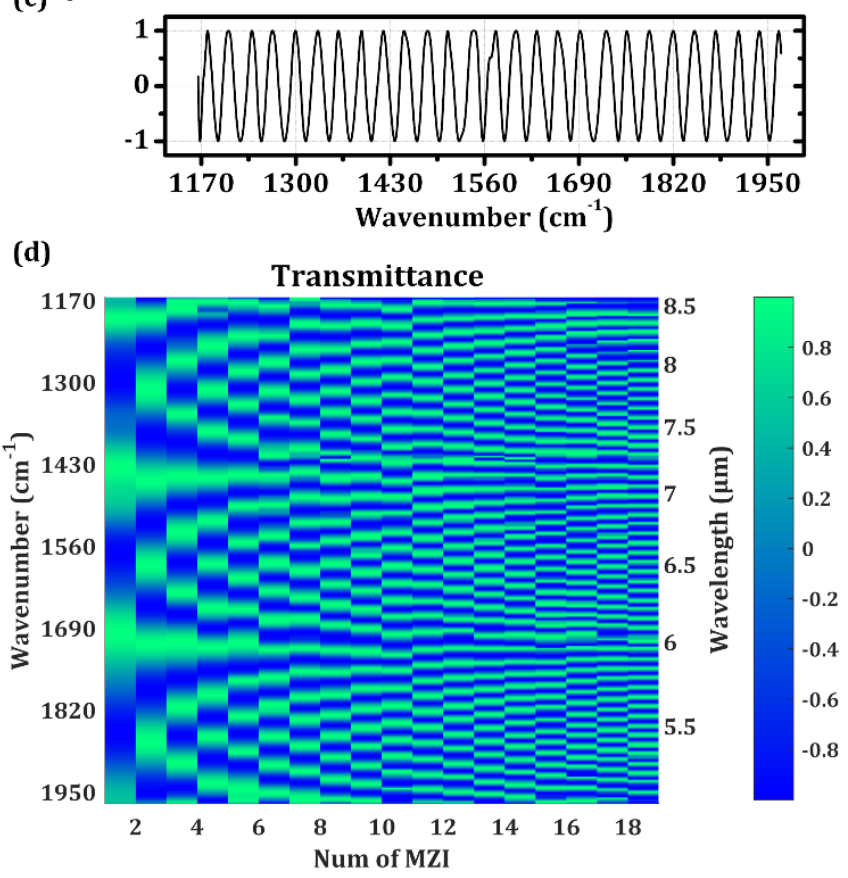
Fig. 2. (a)-(c) Example of an interferogram pattern from a MZI with $\Delta \mathrm{L}=84.6 \mu \mathrm{m}$. The mean value (red curve in (a)) and the envelop wavefunction (green curve in (b)) are subtracted to obtain the curve shown in (c); (d) Experimental transmittance spectra for the fundamental transverse electric (TE) mode for each 19 MZIs in the interferometer array of the spectrometer.

The on-chip spectrometer comprises 19 MZIs, arranged in a multi-aperture configuration, having total footprint of $1.5 \mathrm{~cm}^{2}$. Optical microscope image of the complete SHFTS is shown in Fig 1.b, and scanning electron microscope image of one MMI is shown in the inset of Fig 1 . b. The maximum path length difference $\left(\Delta \mathrm{L}_{\max }\right)$ and the number of interferometers $(\mathrm{N})$ determine the resolution $(\delta v)$ and the free spectral range (FSR) of the spectrometer expressed in wavenumber as [12]:

$$
\begin{gathered}
\delta v=\frac{1}{\Delta L_{\max } n_{G}} \quad\left[\mathrm{~cm}^{-1}\right] \\
F S R=\frac{\delta v N}{2} \quad\left[\mathrm{~cm}^{-1}\right]
\end{gathered}
$$

where $\mathrm{n}_{\mathrm{G}}$ is the group index. Considering a group index of 4.04, a maximum path-length difference of $\Delta \mathrm{L}_{\max }=178.6 \mu \mathrm{m}$ and $\mathrm{N}=19$ a theoretical resolution of $13.8 \mathrm{~cm}^{-1}$ and a FSR of $132 \mathrm{~cm}^{-1}$ is obtained. Note that the resolution of the spectrometer also influences the photometric accuracy, i.e. the ability to monitoring a given absorption peak because of the convolution of the real spectrum with the spectrometer response [30].

The experimental set-up uses tunable external cavity-based quantum cascade lasers covering the $1170 \mathrm{~cm}^{-1}$ to $2000 \mathrm{~cm}^{-1}$ spectral range. Each laser operates in a pulsed regime with a duty cycle of 5\%, a $100 \mathrm{kHz}$ repetition rate, and a maximal mean power of $15 \mathrm{~mW}$ at $1540 \mathrm{~cm}^{-1}$. A polarization controller was used to set the input polarization to either TE or TM respectively. The light is then butt-coupled from free space in and out of each MZI by means of aspheric ZnSe lenses and on-chip adiabatic tapers. An MCT photodetector is then used to record the transmission. The measured transmissions are compatible with flat $2 \mathrm{~dB} / \mathrm{cm}$ waveguide losses and less than $1 \mathrm{~dB}$ insertion loss for each $\mathrm{MMI}$ in the entire spectral range and for both polarizations as reported in previous works [26,29].

To validate the good operation of the proposed SHFTS, the spectrum of the input signal is reconstructed by a transformation matrix retrieval algorithm that provides effective correction of phase and amplitude errors arising from fabrication imperfections [9]. In this algorithm, the output of each MZI is recorded, forming the spatial interferogram $y$ of the input signal. The input spectrum is then retrieved multiplying the interferogram $y$ by the pseudoinverse of the calibration matrix $T$, containing the transmission spectrum of each MZI. The calibration matrix, T, is constructed by recording the spectrum of each MZI. Data processing is used to remove imperfections from the raw measurements, like the frequency dependence of the laser power. This data processing comprises two steps, which are illustrated in Fig. 2: (i) subtraction of the mean value of the transmittance (red curve in Fig 2.a), (ii) division by the envelope wavefunction (green curve in Fig 2.b). The normalized transmittance spectrum is reported in Fig 2.c. This data treatment has been done for both TE and TM calibration matrixes. The insertion loss of MZI is measured as less than $1 \mathrm{~dB}$ for the full range of used laser both for TE and TM polarizations. The final calibration matrix $T$ for TE polarization is reported in Fig 2.d.
Generally, fabrication errors produce phase shifts that may distort the interferogram. This typically results in a misalignment of the outputs spectrum of the MZIs. Interestingly, the reported SHFTS interferogram shows quite good alignment, without any phase error correction in the data processing. For instance, all MZI reach maximum transmission (Littrow frequency [30]) for frequencies of 1185,1450 and $1715 \mathrm{~cm}^{-1}$ separated by two times the FSR of the SHFS. This is a clear evidence of low phase distortion, proving the robustness of the Ge-rich SiGe waveguides to fabrication imperfections.

(a)

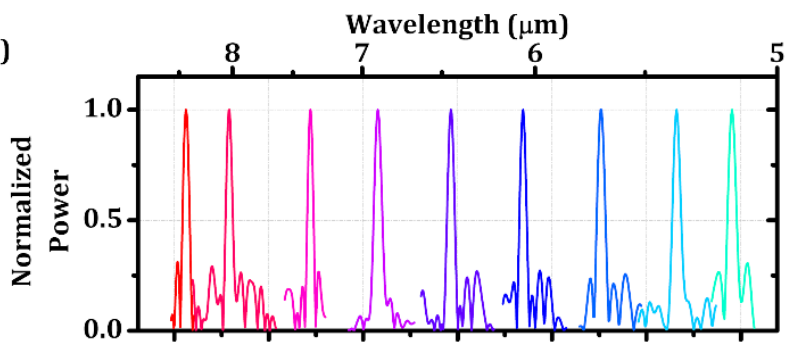

(b)

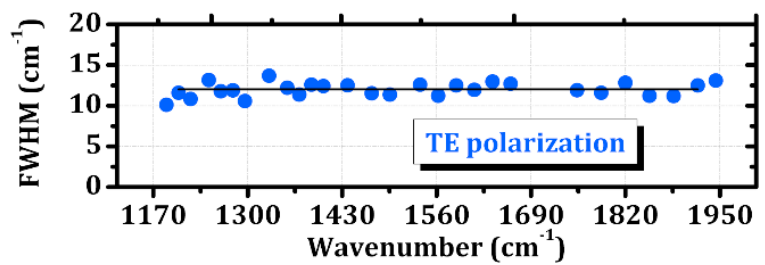

(c)

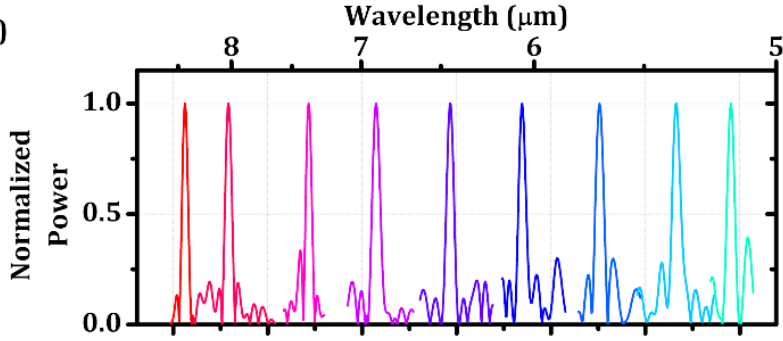

(d)

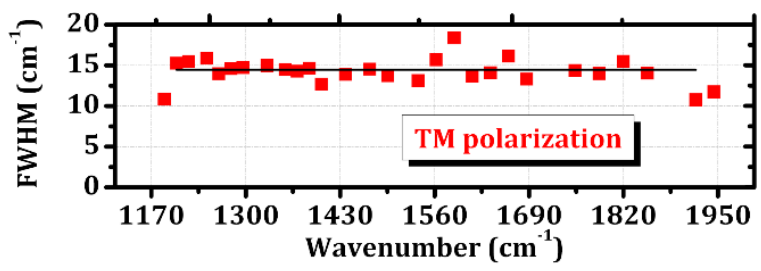

Fig. 3. Experimentally retrieved spectra for a monochromatic input scanned between $1170 \mathrm{~cm}-1$ and $1950 \mathrm{~cm}-1$ for TE (a) and TM (c) polarizations; (b) and (d) report the FWHM of the retrieved signals in TE and TM polarization respectively.

Figure 3 shows the experimental signal spectra retrieved for a monochromatic input scanned along the full operation range and for both for TE (Fig. 3.a) and TM (Fig 3.c) polarizations. The Ge-rich SiGe spectrometer allows spectral retrieval in a wavelength range of $800 \mathrm{~cm}^{-1}$ centered at $1560 \mathrm{~cm}^{-1}$. Note that, at each input frequency, a spectral range narrower than the FSR of $132 \mathrm{~cm}^{-1}$ has been considered. A Gaussian apodization window is applied in the spectral domain to reduce truncation ripple [30]. The resolution of the SHFTS, measured at full width at half-maximum (FWHM) of the retrieved signals, are evaluated at $12 \mathrm{~cm}^{-1}$ and $14.5 \mathrm{~cm}^{-1}$ for TE and 
TM polarizations, respectively (see Figs 3.c and 3.d). By building two calibration matrices, for TE and TM polarizations respectively, our SHFTS can be operated with any of the two polarizations. Still, only one (TE or TM) should be injected into the chip to enable proper spectral retrieval.

Finally, to evaluate the robustness of the proposed SHFTS we repeated the signal retrieval a few weeks after, using the calibration matrix built in previous experiment. Both the device resolution and eventual temperature variations in the chip (which is not controlled in our setup) could create errors in the retrieved spectrum. Interestingly, comparing the peak wavelength of the retrieved signal with the input wavelength, the error in frequency retrieval is always below $2 \mathrm{~cm}^{-1}$.

In conclusion, a SHFTS working both in TE and TM polarization based on Ge-rich SiGe waveguide has been reported. Broadband operation is one of the key advantage of this MIR platform and is explained by the self-mode re-adaptation effect due to the graded refractive index profile [26]. The demonstrated on-chip SHFTS accounts for an operating frequency range of $800 \mathrm{~cm}^{-1}$, a FSR of $132 \mathrm{~cm}^{-1}$ and a resolution below $15 \mathrm{~cm}^{-1}$ for the studied wavelength range. In terms of precision of the retrieved signal, the frequency error is below $2 \mathrm{~cm}^{-1}$ when using a calibration matrix measured a few weeks before. Interestingly, low phase errors have been demonstrated, indicating a good robustness of the waveguide design and fabrication against fluctuations of the waveguide effective index and optical path.

These results provide the first experimental demonstration of on-chip MIR silicon germanium-based Fourier-transform spectrometer. The device resolution and FSR can be seamlessly designed by increasing the number of Mach Zehnder interferometers or by tuning the phase delay. The resolution of the SHFTS can be further improved by exploiting advanced numerical techniques, like compressive-sensing, developed for Fourier transform spectrometers working in the near-infrared, at $1.55 \mu \mathrm{m}$ wavelength [31]. It is also possible to combine the Ge-rich SiGe interferometers with digital Fourier Transform Spectrometers [11] to reach resolution below $1 \mathrm{~cm}^{-1}$ while maintaining FSR larger than $100 \mathrm{~cm}^{-1}$. Finally, the on-chip integration of sensing circuits with the FT spectrometer could pave the way for future demonstration of robust, high resolution, and cost-effective multi-target spectrometers covering an ultra-wide band of the fingerprint wavelength range.

Funding. European Research Council (ERC) under the European Union's Horizon 2020 research and innovation program $\left(\mathrm{N}^{\circ} 639107\right.$ INsPIRE).

Acknowledgment. The fabrication of the device was performed at the Plateforme de Micro-Nano-Technologie/C2N, which is partially funded by the "Conseil Général de l'Essonne". This work was partly supported by the French RENATECH network.

\section{References}

1. S. Rehman, Z. Movasaghi, J. A. Darr, and I. U. Rehman, Appl. Spectrosc. Rev. 45, 355 (2010).

2. J. Depciuch, E. Kaznowska, I. Zawlik, R. Wojnarowska, M. Cholewa, P. Heraud, and J. Cebulski, Appl. Spectrosc. 70, 251 (2016).

3. L. Labadie and O. Wallner, Opt. Express 17, 1947 (2009).

4. Q. Liu, J. M. Ramirez, V. Vakarin, X. Le Roux, A. Ballabio, J. Frigerio, D. Chrastina, G. Isella, D. Bouville, L. Vivien, C. A. Ramos, and D. MarrisMorini, Opt. Mater. Express 8, 1305 (2018).
5. L. Tombez, E. J. Zhang, J. S. Orcutt, S. Kamlapurkar, and W. M. J. Green, Optica 4, 1322 (2017).

6. Y. C. Chang, P. Wägli, V. Paeder, A. Homsy, L. Hvozdara, P. Van Der Wal, J. Di Francesco, N. F. De Rooij, and H. Peter Herzig, Lab Chip 12, 3020 (2012).

7. A. Vasiliev, M. Muneeb, J. Allaert, J. Van Campenhout, R. Baets, and G. Roelkens, IEEE J. Sel. Top. Quantum Electron. 24, (2018).

8. X. Ma, M. Li, and J. J. He, IEEE Photonics J. 5, (2013).

9. A. V. Velasco, P. Cheben, P. J. Bock, A. Delâge, J. H. Schmid, J. Lapointe, S. Janz, M. L. Calvo, D.-X. Xu, M. Florjańczyk, and M. Vachon, Opt. Lett. 38, 706 (2013).

10. M. C. M. M. Souza, A. Grieco, N. C. Frateschi, and Y. Fainman, Nat. Commun. 9, 1 (2018)

11. D. M. Kita, B. Miranda, D. Favela, D. Bono, J. Michon, H. Lin, T. Gu, and J. $\mathrm{Hu},(2018)$.

12. M. Nedeljkovic, A. V. Velasco, A. Z. Khokhar, A. Delage, P. Cheben, and G. Z. Mashanovich, IEEE Photonics Technol. Lett. 28, 528 (2016).

13. D. F. V. James, J. Opt. Soc. Am. A 11, 1641 (1994).

14. L. He, Y. Guo, Z. Han, K. Wada, L. C. Kimerling, J. Michel, A. M. Agarwal, G. Li, and L. Zhang, Opt. Lett. 42, 3454 (2017).

15. M. G. Hansen, I. Ernsting, S. V. Vasilyev, A. Grisard, E. Lallier, B. Gérard, and S. Schiller, Opt. Express 21, 27043 (2013).

16. C. Gilles, L. J. Orbe, G. Carpintero, G. Maisons, and M. Carras, Opt. Express 23, 20288 (2015).

17. H. Lin, L. Li, Y. Zou, S. Danto, J. D. Musgraves, K. Richardson, S. Kozacik, M. Murakowski, D. Prather, P. T. Lin, V. Singh, A. Agarwal, L. C. Kimerling, and J. Hu, Opt. Lett. 38, 1470 (2013).

18. A. Gutierrez-Arroyo, E. Baudet, L. Bodiou, J. Lemaitre, I. Hardy, F. Faijan, B. Bureau, V. Nazabal, and J. Charrier, Opt. Express 24, 23109 (2016).

19. J. S. Penadés, A. Sánchez-Postigo, M. Nedeljkovic, A. Ortega-Moñux, J. G. Wangüemert-Pérez, Y. Xu, R. Halir, Z. Qu, A. Z. Khokhar, A. Osman, W. Cao, C. G. Littlejohns, P. Cheben, I. Molina-Fernández, and G. Z. Mashanovich, 26, 528 (2017).

20. A. Malik, M. Muneeb, S. Pathak, Y. Shimura, J. Van Campenhout, R. Loo, and G. Roelkens, IEEE Photonics Technol. Lett. 25, 1805 (2013).

21. A. Malik, S. Dwivedi, L. Van Landschoot, M. Muneeb, Y. Shimura, G. Lepage, J. Van Campenhout, W. Vanherle, T. Van Opstal, R. Loo, and G. Roelkens, Opt. Express 22, 28479 (2014).

22. M. Yang, Y. Guo, J. Wang, Z. Han, K. Wada, L. C. Kimerling, A. M. Agarwal, J. Michel, G. Li, and L. Zhang, Opt. Express 25, 16116 (2017). 23. M. Sinobad, C. Monat, B. Luther-davies, P. Ma, S. Madden, D. J. Moss, A. Mitchell, D. Allioux, R. Orobtchouk, S. Boutami, J.-M. Hartmann, J.-M. Fedeli, and C. Grillet, Optica 5, 360 (2018).

24. P. Barritault, M. Brun, P. Labeye, J.-M. Hartmann, F. Boulila, M. Carras, and S. Nicoletti, Opt. Express 23, 26168 (2015).

25. M. Brun, P. Labeye, G. Grand, J.-M. Hartmann, F. Boulila, M. Carras, and S. Nicoletti, Opt. Express 22, 508 (2014).

26. J. M. Ramirez, Q. Liu, V. Vakarin, J. Frigerio, A. Ballabio, X. Le Roux, D. Bouville, L. Vivien, G. Isella, and D. Marris-Morini, Opt. Express 26, 870 (2018).

27. S. Serna, V. Vakarin, J. M. Ramirez, J. Frigerio, A. Ballabio, X. Le Roux, L. Vivien, G. Isella, E. Cassan, N. Dubreuil, and D. Marris-Morini, Sci. Rep. 7, 1 (2017).

28. J. M. Ramirez, V. Vakarin, J. Frigerio, P. Chaisakul, D. Chrastina, X. Le Roux, A. Ballabio, L. Vivien, G. Isella, and D. Marris-Morini, 25, 3020 (2017). 29. V. Vakarin, J. M. Ramírez, J. Frigerio, A. Ballabio, X. Le Roux, Q. Liu, D. Bouville, L. Vivien, G. Isella, and D. Marris-Morini, Opt. Lett. 42, 3482 (2017).

30. P. R. Griffiths and J. A. de Haseth, Fourier Transform Infrared Spectrometry (John Wiley \& Sons, Inc., Hoboken, NJ, USA, 2007). 31. H. Podmore, A. Scott, P. Cheben, A. V. Velasco, J. H. Schmid, M. Vachon, and R. Lee, 42, 1440 (2017). 


\section{REFERENCES}

1. S. Rehman, Z. Movasaghi, J. A. Darr, and I. U. Rehman, Appl. Spectrosc. Rev. 45, 355 (2010).

2. J. Depciuch, E. Kaznowska, I. Zawlik, R. Wojnarowska, M. Cholewa, P. Heraud, and J. Cebulski, Appl. Spectrosc. 70, 251 (2016).

3. L. Labadie and O. Wallner, Opt. Express 17, 1947 (2009).

4. Q. Liu, J. M. Ramirez, V. Vakarin, X. Le Roux, A. Ballabio, J. Frigerio, D.

Chrastina, G. Isella, D. Bouville, L. Vivien, C. A. Ramos, and D. Marris-

Morini, Opt. Mater. Express 8, 1305 (2018).

5. L. Tombez, E. J. Zhang, J. S. Orcutt, S. Kamlapurkar, and W. M. J. Green, Optica 4, 1322 (2017).

6. Y. C. Chang, P. Wägli, V. Paeder, A. Homsy, L. Hvozdara, P. Van Der Wal, J. Di Francesco, N. F. De Rooij, and H. Peter Herzig, Lab Chip 12, 3020 (2012).

7. A. Vasiliev, M. Muneeb, J. Allaert, J. Van Campenhout, R. Baets, and G. Roelkens, IEEE J. Sel. Top. Quantum Electron. 24, (2018).

8. X. Ma, M. Li, and J. J. He, IEEE Photonics J. 5, (2013).

9. A. V. Velasco, P. Cheben, P. J. Bock, A. Delâge, J. H. Schmid, J. Lapointe, S. Janz, M. L. Calvo, D.-X. Xu, M. Florjańczyk, and M. Vachon, Opt. Lett. 38, 706 (2013).

10. M. C. M. M. Souza, A. Grieco, N. C. Frateschi, and Y. Fainman, Nat. Commun. 9, 1 (2018).

11. D. M. Kita, B. Miranda, D. Favela, D. Bono, J. Michon, H. Lin, T. Gu, and J. $\mathrm{Hu},(2018)$.

12. M. Nedeljkovic, A. V. Velasco, A. Z. Khokhar, A. Delage, P. Cheben, and G. Z. Mashanovich, IEEE Photonics Technol. Lett. 28, 528 (2016).

13. D. F. V. James, J. Opt. Soc. Am. A 11, 1641 (1994).

14. L. He, Y. Guo, Z. Han, K. Wada, L. C. Kimerling, J. Michel, A. M. Agarwal, G. Li, and L. Zhang, Opt. Lett. 42, 3454 (2017).

15. M. G. Hansen, I. Ernsting, S. V. Vasilyev, A. Grisard, E. Lallier, B. Gérard, and S. Schiller, Opt. Express 21, 27043 (2013).

16. C. Gilles, L. J. Orbe, G. Carpintero, G. Maisons, and M. Carras, Opt. Express 23, 20288 (2015).

17. H. Lin, L. Li, Y. Zou, S. Danto, J. D. Musgraves, K. Richardson, S. Kozacik, M. Murakowski, D. Prather, P. T. Lin, V. Singh, A. Agarwal, L. C. Kimerling, and J. Hu, Opt. Lett. 38, 1470 (2013).

18. A. Gutierrez-Arroyo, E. Baudet, L. Bodiou, J. Lemaitre, I. Hardy, F. Faijan, B. Bureau, V. Nazabal, and J. Charrier, Opt. Express 24, 23109 (2016).

19. J. S. Penadés, A. Sánchez-Postigo, M. Nedeljkovic, A. Ortega-Moñux, J. G. Wangüemert-Pérez, Y. Xu, R. Halir, Z. Qu, A. Z. Khokhar, A. Osman, W.

Cao, C. G. Littlejohns, P. Cheben, I. Molina-Fernández, and G. Z.

Mashanovich, 26, 528 (2017).

20. A. Malik, M. Muneeb, S. Pathak, Y. Shimura, J. Van Campenhout, R. Loo, and G. Roelkens, IEEE Photonics Technol. Lett. 25, 1805 (2013).

21. A. Malik, S. Dwivedi, L. Van Landschoot, M. Muneeb, Y. Shimura, G. Lepage, J. Van Campenhout, W. Vanherle, T. Van Opstal, R. Loo, and G. Roelkens, Opt. Express 22, 28479 (2014).

22. M. Yang, Y. Guo, J. Wang, Z. Han, K. Wada, L. C. Kimerling, A. M. Agarwal, J. Michel, G. Li, and L. Zhang, Opt. Express 25, 16116 (2017).

23. M. Sinobad, C. Monat, B. Luther-davies, P. Ma, S. Madden, D. J. Moss, A. Mitchell, D. Allioux, R. Orobtchouk, S. Boutami, J.-M. Hartmann, J.-M. Fedeli, and C. Grillet, Optica 5, 360 (2018).

24. P. Barritault, M. Brun, P. Labeye, J.-M. Hartmann, F. Boulila, M. Carras, and S. Nicoletti, Opt. Express 23, 26168 (2015).

25. M. Brun, P. Labeye, G. Grand, J.-M. Hartmann, F. Boulila, M. Carras, and S. Nicoletti, Opt. Express 22, 508 (2014).

26. J. M. Ramirez, Q. Liu, V. Vakarin, J. Frigerio, A. Ballabio, X. Le Roux, D. Bouville, L. Vivien, G. Isella, and D. Marris-Morini, Opt. Express 26, 870 (2018).

27. S. Serna, V. Vakarin, J. M. Ramirez, J. Frigerio, A. Ballabio, X. Le Roux, L. Vivien, G. Isella, E. Cassan, N. Dubreuil, and D. Marris-Morini, Sci. Rep. 7, 1 (2017).

28. J. M. Ramirez, V. Vakarin, J. Frigerio, P. Chaisakul, D. Chrastina, X. Le Roux, A. Ballabio, L. Vivien, G. Isella, and D. Marris-Morini, 25, 3020 (2017). 29. V. Vakarin, J. M. Ramírez, J. Frigerio, A. Ballabio, X. Le Roux, Q. Liu, D. Bouville, L. Vivien, G. Isella, and D. Marris-Morini, Opt. Lett. 42, 3482 (2017).

30. P. R. Griffiths and J. A. de Haseth, Fourier Transform Infrared
Spectrometry (John Wiley \& Sons, Inc., Hoboken, NJ, USA, 2007). 31. H. Podmore, A. Scott, P. Cheben, A. V. Velasco, J. H. Schmid, M. Vachon, and R. Lee, 42, 1440 (2017). 